\title{
Solusi Numerik Model Umum Epidemik Susceptible, Infected, Recovered (SIR) dengan Menggunakan Metode Modified Milne-Simpson
}

\author{
Wahyudin Nur ${ }^{1}$, Nurul Mukhlisah Abdal $^{2}$ \\ ${ }^{1}$ Program Studi Matematika FMIPA Universitas Sulawesi Barat \\ ${ }^{2}$ Jurusan Pendidikan Teknik Informatika Univerditas Negeri Makassar \\ e-mail: ${ }^{1}$ wnalafkar93@gmail.com, ${ }^{2}$ nurulmukhlisah@gmail.com
}

\begin{abstract}
Abstrak
Model Epidemik Susceptible, Infected, Recovered (SIR) merupakan salah satu metode yang paling banyak digunakan untuk memodelkan penyebaran penyakit. Model ini biasa digunakan untuk simulasi dan ptediksi jumlah kasus penyakit tertentu. Dalam artikel ini penulis melakukan simulasi dan mencari solusi numerik model umum epidemik SIR dengan menggunakan MMetode Modified Milne Simpson yang dipadukan dengan metode Runge Kutta Orde 4. Metode ini merupakan salah satu metode prediktor korektor yang biasa digunakan untuk mencari solusi numerik persamaan diferensial.. Dengan menggunakan parameter $\mu=0,1 ; \lambda=0,0098 ; \gamma=0,5$ diperoleh $r_{0}=0,016333<1$. Kurva kelas Infected menuju nol dan setimbang dititik nol. Hal ini menandakan, dengan pemilihan parameter seperti itu, kelas Infected akan menghilang dari populasi. Berdasarkan hasil simulasi, dapat disipulkan bahwa metode Milne Simpson layak digunakan untuk menentukan solusi numerik model umum epidemik SIR.
\end{abstract}

Kata kunci: Model SIR, Modified Milnw Simpson, Runge Kutta Orde 4

\section{PENDAHULUAN}

Perkembangan penelitian dalam bidang pemodelan epidemik sangat pesat. Salah satu model epidemik yang paling banyak digunakan adalah model epidemik SIR. Model ini kebanyakan digunakan untuk penyakit demam berdarah dan TBC, seperti yang dilakukan oleh Syafruddin S. dan M.S.M. Noorani (2013). Dalam artikel ini, hal yang menjadi pokok pembahasan adalah penggunaan metode milne-simpson untuk menyelesaikan sistem persamaan diferensial model umum SIR.

Untuk solusi numerik model epidemik SIR, sebenarnya sudah ada beberapa artikel yang membahasnya. Beberapa artiel memaparkan solusi numerik dicari dengan menggunakan metode Runge Kutta Orde 4 (M. Khalid, M. Sultana dan F.S. Khan. 2015) dan Homotopy Perturbation Method (Rangkuti, YM, Syafruddin S. dan M.S.M. Noorani. 2014 ). Dalam artikel ini, penulis melakukan analisis numerik dengan menggunakan Metode Milne-Simpson berbantuan Matlab. Metode ini merupakan salah satu metode yang biasa disebut prediktor dan korektor.

Berbeda dengan metode Runge Kutta Orde 4. Metode ini memerlukan nilai awal yang lebih banyak sebelum diiterasikan dengan menggunakan metode Milne-Simpson. Hal inilah yang membuat metode ini disebut metode banyak langkah. Nilai awal tersebut biasanya dicari dengan menggunakan metode lain, misalnya metode Euler. Namun kali ini, penulis memadukan antara metode RK4 dengan metode Milne-Simpson. 


\section{METODE PENELITIAN}

Dalam partikel ini, penulis memadukan metode RK4 dengan Modified Milne Simpson. Pertama tama penulis akan menggunakan metode RK4 untuk mencari nilai hingga 4 langkah. Setelah diperoleh data 4 langkah, maka dilanjutkan dengan metode Milne-Simpson. Model SIR yang akan digunakan adalah model umum SIR seperti yang digunakan oleh Ullah Roman 2013. Model SIR kemudian diubah kebentuk diskrit sehingga solusinya dapat ditentukan dengan menggunakan metode numerik. Setelah diperoleh model diskritnya, selanjutnya penulis membuat software dengan menggunakan Matlab dan melakukan simulasi numerik.

\section{HASIL DAN PEMBAHASAN}

Model umum SIR dapat dinyatakan sesuai dengan persamaan di bawah:

$$
\begin{aligned}
& \frac{d S(t)}{d t}=\mu-\lambda S(t) I(t)-\mu S(t) \\
& \frac{d I(t)}{d t}=\lambda S(t) I(t) I(t)-\gamma_{1} I(t)-\mu I(t) \\
& \frac{d R(t)}{d t}=\gamma_{1} I(t)-\mu R(t)
\end{aligned}
$$

dengan $S(t)$ adalah kelas yang rentan terkena penyakit (susceptible), $I(t)$ adalah kelas orang yang sakit (infected), $R(t)$ adalah kelas orang yang telah sembuh (recovered), $\mu$ adalah laju pertumbuhan dan kematian, $\lambda$ adalah laju penularan penyakit jika orang rentan melakukan kontak dengan orang sakit, $\gamma_{1}$ adalah laju kesembuhan pasien. syarat awalnya $S(t) \geq 0, I(t) \geq 0$, dan $R(t) \geq 0$. Bilangan basic repdoduction yang sesuai dengan model (1) dinyatakan dengan persamaan $r_{0}=\frac{\lambda}{\mu+\gamma}$.

Selanjutnya model (1) diubah kebentuk diskrrit

$$
\begin{aligned}
& f\left(t_{i}, S_{i}, I_{i}, R_{i}\right)=\frac{d S(t)}{d t}=\mu-\lambda S_{i} I_{i},-\mu S_{i} \\
& g\left(t_{i}, S_{i}, I_{i}, R_{i}\right)=\frac{d I(t)}{d t}=\lambda S_{i} I_{i}-\gamma_{1} I_{i}-\mu I_{i} \\
& o\left(t_{i}, S_{i}, I_{i}, R_{i}\right)=\frac{d R(t)}{d t}=\gamma_{1} I_{i}-\mu R_{i}
\end{aligned}
$$

Nilai $S_{i}, I_{i}, R_{i}(i=1,2,3)$ akan ditentukan dengan menggunakan metode Runge Kutta Orde 4 (RK4) sesuai dengan persamaan di bawah:

$$
\begin{aligned}
& S_{i+1}=S_{i}+\frac{1}{6} h\left(q_{1}^{f}+2 q_{2}^{f}+2 q_{3}^{f}+q_{4}^{f}\right) \\
& I_{i+1}=I_{i}+\frac{1}{6} h\left(q_{1}^{g}+2 q_{2}^{g}+2 q_{3}^{g}+q_{4}^{g}\right) \\
& R_{i+1}=I_{i}+\frac{1}{6} h\left(q_{1}^{o}+2 q_{2}^{o}+2 q_{3}^{o}+q_{4}^{o}\right)
\end{aligned}
$$

dengan

$$
\begin{aligned}
& q_{1}^{f}=f\left(t_{i}, S_{i}, I_{i}, R_{i}\right) \\
& q_{1}^{g}=g\left(t_{i}, S_{i}, I_{i}, R_{i}\right) \\
& q_{1}^{o}=o\left(t_{i}, S_{i}, I_{i}, R_{i}\right)
\end{aligned}
$$




$$
\begin{aligned}
& q_{2}^{f}=f\left(t_{i}+\frac{1}{2} h, S_{i}+\frac{q_{1}^{f} h}{2}, I_{i}+\frac{q_{1}^{g} h}{2}, R_{i}+\frac{q_{1}^{o} h}{2}\right) \\
& q_{2}^{g}=g\left(t_{i}+\frac{1}{2} h, S_{i}+\frac{q_{1}^{f} h}{2}, I_{i}+\frac{q_{1}^{g} h}{2}, R_{i}+\frac{q_{1}^{o} h}{2}\right) \\
& q_{2}^{o}=o\left(t_{i}+\frac{1}{2} h, S_{i}+\frac{q_{1}^{f} h}{2}, I_{i}+\frac{q_{1}^{g} h}{2}, R_{i}+\frac{q_{1}^{o} h}{2}\right) \\
& q_{3}^{f}=f\left(t_{i}+\frac{1}{2} h, S_{i}+\frac{q_{2}^{f} h}{2}, I_{i}+\frac{q_{2}^{g} h}{2}, R_{i}+\frac{q_{2}^{o} h}{2}\right) \\
& q_{3}^{g}=g\left(t_{i}+\frac{1}{2} h, S_{i}+\frac{q_{2}^{f} h}{2}, I_{i}+\frac{q_{2}^{g} h}{2}, R_{i}+\frac{q_{2}^{o} h}{2}\right) \\
& q_{3}^{o}=o\left(t_{i}+\frac{1}{2} h, S_{i}+\frac{q_{2}^{f} h}{2}, I_{i}+\frac{q_{2}^{g} h}{2}, R_{i}+\frac{q_{2}^{o} h}{2}\right) \\
& q_{4}^{f}=f\left(t_{i}+\frac{1}{2} h, S_{i}+q_{3}^{f} h, I_{i}+q_{3}^{g} h, R_{i}+q_{3}^{o} h\right) \\
& q_{4}^{g}=g\left(t_{i}+\frac{1}{2} h, S_{i}+q_{3}^{f} h, I_{i}+q_{3}^{g} h, R_{i}+q_{3}^{o} h\right) \\
& q_{4}^{o}=o\left(t_{i}+\frac{1}{2} h, S_{i}+q_{3}^{f} h, I_{i}+q_{3}^{g} h, R_{i}+q_{3}^{o} h\right)
\end{aligned}
$$

Setelah diperoleh $S_{i}, I_{i}, R_{i}(i=1,2,3)$, dilanjut dengan metode Modified Milne-Simpson

$$
\begin{aligned}
& S_{i+1}=S_{i-1}+\frac{h}{3}\left(f_{i-1}+4 f_{i}+f_{i+1}\right) \\
& I_{i+1}=I_{i-1}+\frac{h}{3}\left(g_{i-1}+4 g_{i}+g_{i+1}\right) \\
& R_{i+1}=R_{i-1}+\frac{h}{3}\left(o_{i-1}+o_{i}+o_{i+1}\right)
\end{aligned}
$$

Dengan

$$
\begin{aligned}
& f_{i+1}=f\left(t_{i+1}, m_{i+1}^{f}, m_{i+1}^{g}, m_{i+1}^{o}\right) \\
& g_{i+1}=g\left(t_{i+1}, m_{i+1}^{f}, m_{i+1}^{g}, m_{i+1}^{o}\right) \\
& o_{i+1}=o\left(t_{i+1}, m_{i+1}^{f}, m_{i+1}^{g}, m_{i+1}^{o}\right) \\
& m_{i+1}^{f}=p_{i+1}^{f}+\frac{28}{29}\left(S_{i}-p_{i}^{f}\right) \\
& m_{i+1}^{g}=p_{i+1}^{g}+\frac{28}{29}\left(I_{i}-p_{i}^{g}\right) \\
& m_{i+1}^{o}=p_{i+1}^{o}+\frac{28}{29}\left(R_{i}-p_{i}^{o}\right) \\
& p_{i+1}^{f}=S_{i-3}+\frac{4 h}{3}\left(2 f_{i-2}-f_{i-1}+2 f_{i}\right) \\
& p_{i+1}^{g}=I_{i-3}+\frac{4 h}{3}\left(2 g_{i-2}-g_{i-1}+2 g_{i}\right) \\
& p_{i+1}^{o}=R_{i-3}+\frac{4 h}{3}\left(2 o_{i-2}-o_{i-1}+2 o_{i}\right)
\end{aligned}
$$


Setelah itu, dilakukan simulasi numerik model SIR dengan menggunakan Modified Milne-Simpson-RK4 berbantuan MATLAB dengan menggunakan parameter $\mu=0,1$

$\lambda=0,0098$

$\gamma=0,5$

Ullah Roman 2013

diperoleh $r_{0}=0,016333$. Berdasarkan kurva grafik 1, dapat terlihat kelas infected menuju 0 seiring berjalannya waktu. Hal ini terjadi karena $r_{0}=0,016333<1$ sebaliknya jika $r_{0}>1$ maka akan terjadi endemik penyakit (penyakit akan selalu ada).

Grafik 1. Simulasi Model Epidemik SIR $\left(r_{0}<1\right)$

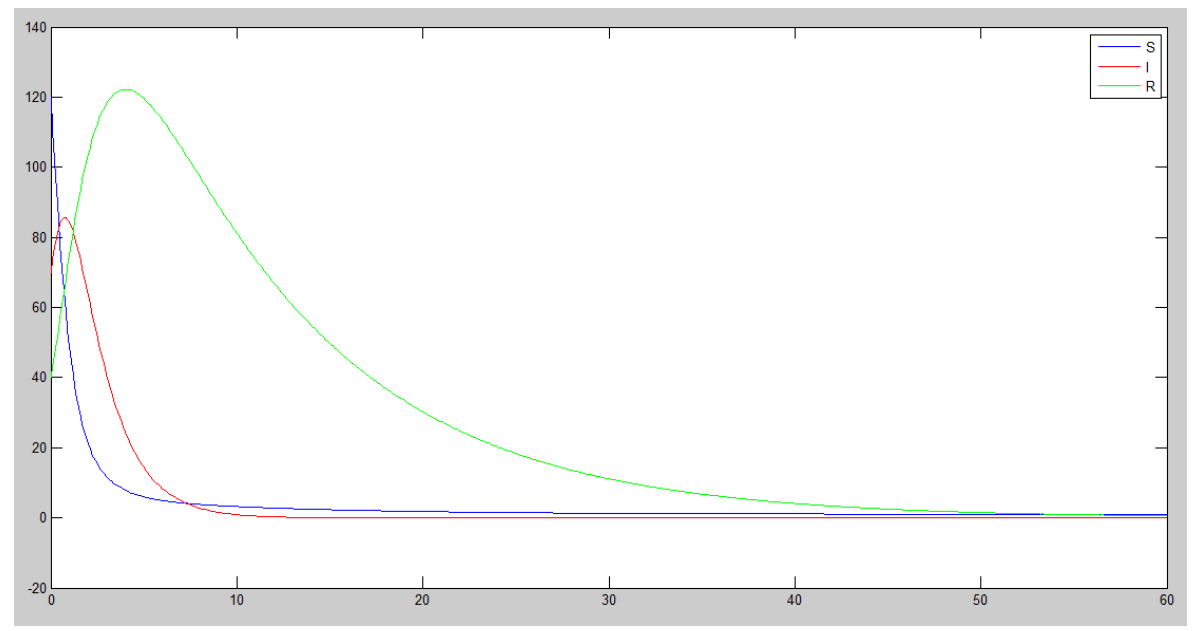

\section{KESIMPULAN}

Metode Modified Milne Simpson merupakan salah satu metode prediktor korektor yang dapat digunakan untuk mencari solusi numerik model epidemik SIR. Dengan menggunakan parameter $\mu=0,1 ; \lambda=0,0098 ; \gamma=0,5$ diperoleh $r_{0}=0,016333<1$ tampak kurva kelas infected menuju nol dan setimbang dititik nol. Hal ini menandakan penyakit akan menghilang. Pada artikel ini, penulis memadukan Metode Modified Milne Simpson dengan Runge Kutta orde 4.

\section{DAFTAR PUSTAKA}

M. Khalid, M. Sultana dan F.S. Khan. 2015. Numerical Solution of SIR Model of Dengue Fever. International Journal of Computer Applications. 118(21):1-4.

Rangkuti, YM, Syafruddin S. dan M.S.M. Noorani. 2014. Numerical Analytic Solution of SIR Model of Dengue Fever Disease in South Sulawesi using Homotopy Perturbation Method and Variational Iteration Method. Journal of Mathematical Fundamental Science. 46(1):91-105. 
Syafruddin S. dan M.S.M. Noorani. 2013. A SIR Model for Spread of Dengue Fever Disease (Simulation for South Sulawesi, Indonesia and Selangor, Malaysia). World Journal of Modelling and Simulation. 9(2):96-105.

Ullah, Roman. Zaman, Gul. Islam, Saeed. 2013. Stability Analysis of A General SIR Epidemic Model. VFAST Transaction on Mathematics. 1(1):16-20. 